\title{
EFEITOS ALELOPATICOS DE ALGUNS EXTRATOS VEGETAIS NA GERMINAÇÃO DO TOMATEIRO (Lycopersicon esculentum Mill. cv. Santa Cruz)
}

\author{
P.R.C. CASTRO*, J.D. RODRIGUES**, M.A. MORAES*** \& V.L.M. CARVALHO*** \\ * Prof. Titular, De pto. de Botânica, E. S. \\ A. "Luiz de Queiroz", USP, CP 9, 13.400 \\ - Piracicaba, SP. \\ ** As s. Dout or, De pto. de Botân ic a, \\ IB BM A, UNESP, Campus de Botucatu, SP. \\ *** Fitofisiologia Ecológica, Curso de Pós - \\ Graduação em Ciências Biológicas - \\ B otânica, UNESP, Campus de Botucatu, SP.
}

\section{RESUMO}

O presente trabalho teve por finalidade avaliar os possíveis efeitos alelopáticos de três plantas daninhas (Cyperus rotundus, Sorghum halepense e Cynodon dactylon), uma leguminosa (Canavalia ensiformis) e colza (Brassica napus), na germinação das sementes do tomateiro (Lycopersicon esculentum cv. Santa Cruz) utilizad o como indicador. Tubérculos de tiririca, rizomas de capim massambará, o sistema radicular de grama seda, além de folhas e raízes de feijão-de-porco e colza, foram homogeneizados em solução aquosa, submetidos a filtração e centrifugação. A aplicação do sobrenadante no substrato de germinação das sementes de tomateiro mostrou afetar o processo germinativo e o desenvolvimento da radícula e do hipocótilo. C. rotundus, $S$. halepense e raízes de C. ensiformis possuem substâncias altamente inibitórias à germinação do tomateiro 'Santa Cruz", sendo que a planta indicadora também mostrou-se sensível às substâncias presentes nas folhas de $B$. napus e em C. dactylon.

Palavras chave: alelopatia, tomateiro, Cyperus rotundus, Sorghum halepense, Canavalia ensiformis, Cynodon dactylon, Brassica napus.

\section{SUMMARY}

The present study was carried out to evaluate the possible allelopathic efecfts of Cyperus rotundus L., Sorghum halepense L., Cynodon dactylon L., Canavalia ensiformis D.C., and Brassica napus L. on seed germination of Lycopersicon esculentum Mill. cv. Santa Cruz. Extracts from tubers of C. rotundus, roots of $S$. halepense and $\mathrm{C}$. dactylon, and leaves and roots of $\mathrm{C}$. ensiform is and B. napus were used to evaluate the effects on tomato seed germination. Aqueous solution of these organs, obtained by homogenization, filtration and centrifugation, were introduced on Petri dishes containing to-

mato seeds. The evaluation of germination showed a strong negative allelop athic effect of C. rotundus tubers, $S$. halepense and C. ensiformis roots on tomato seeds. Extracts from leaves of $B$. napus and C. dactylon roots inhibited germination of 'Santa Cruz' tomato seed also.

\section{INTRODUÇÃO}

Alelopatia vem a ser qualquer efeito benéfico ou prejudicial, direto ou indireto, causado por uma planta (ou microorg ani smo) em outra, através da libera ção de substância orgânica no ambiente. Em um documento japonês de 300 anos atrás, Banzan Kumazawa relatou que a água da chuva que lava as folhas de Pinus densiflora é prejudicial aos vegetais que se desenvolvem sob a árvore. Substâncias exsudadas pelas raízes de Pisum arvense podem estimular a fotossíntese e a absorção de nutrientes por plantas de cevada.

As substâncias alelopáticas são geralmente classificadas como compostos secundários das plantas, sendo que a maioria se origina de acetato ou de aminoácidos da via bioquímica. Entretanto, há considerável diversid ade química entre estes compostos, podendo ser ácidos fenólicos, cumarina, terpenóides, alcalóides, flavonóides, etileno e várias outras substâncias. Numerosos compostos alelopáticos produ zidos pelas plantas cultivadas, que se mostram inibitórios para diversas plantas daninhas, devem agir como eficientes herbicidas naturais. A pre- 
sença de fitotoxinas no solo se deve, geralmente, a percolação das substâncias da planta durante a chuva, a exsudação pelas raízes e a decomposição de resíduos vegetais (10).

$\mathrm{O}$ tomateiro tem-se mostrado bastante sensível ao efeito de compostos alelopáticos. Juglona, uma toxina extraída de raízes e casca de Juglans nigra, inibe o desenvolvimento do tomateiro, sendo que na superfície do solo, delimitada pelo crescimento das raízes desta nogueira, também verifica-se inibição do desenvolvimento de alfafa (7). Folhas de Parthenium hysterophorus, incorporadas ao solo, apresentam efeitos negativos sobre o tomateiro (5). Também se verificou que 0,1 a $1,0 \%$ de folhas de Euphorbia escala, adicionadas ao solo, promoveram inibição no crescimento de Lycopersicon esculentum. Folhas de Calca cuncifolia têm pronunciado efeito inibitório sobre a germinação do tomateiro cultivar Santa Cruz (3). Por outro lado, observou-se que a incorporação de alfafa (Medicago sativa) ao solo promoveu maior produtividade em tomateiro. Foi isolado um componente químico, o triacontanol, presente nos extratos de alfafa, sendo que este composto pode ser utilizado como um estimulante vegetal $(10,4)$.

Frequentemente o efeito alelopático não interfere apenas nas plantas presentes no momento, mas também em culturas subsequentes. Tubérculos de tiririca (Cyperus rotundus) contém substâncias inibitórias para plantas cultivadas, sendo que a incorporação desta planta daninha ao solo, poderá inibir o desenvolvimento de outras plantas que vierem a ser cultivadas no local (10). 0 desenvolvimento da planta de milho, por exemplo, pode ser inibido por resíduos de raízes ou extratos de Cyperus esculentus (1). Extratos de tubérculos de $C$. esculentus var. aureus inibiram a germinação e crescimento de tomateiro, sendo que foram identificados cinco ácidos fenólicos ativos, além de quatro outras toxinas não identificadas (12).
Observou-se que determinadas culturas podem ser utilizadas para suprimir crescimento de plantas daninhas, sendo que Sorghum vulgare constitue uma dessas culturas (8). Uma das espécies mais estudadas com relação ao potencial alelopático é Sorghum halepense. Quando esta espécie é abundante em um campo abandonado, ela permanece como uma das principais nos primeiros estágios da sucessão vegetal. Ela ocorre muitas vezes como predominante e praticamente única, sugerindo que possue algo mais do que uma excelente habilidade para competir por luz, nutrientes e água. Verificou-se que extrato de rizomas de $S$. hale-pense e também o solo retirado da rizosfera desta espécie foram inibitórios para

o desenvolvimento das raízes primárias de plântulas de arroz e de outras espécies avaliadas (10). Observou-se a presença de fitotoxinas em Cynodon dactylon. Extrato aquoso das folhas desta espécie inibiu a germinação e o crescimento da radícula de alfafa (2). 0 sistema radicular de Canavalia ensiformis exerceu ação inibitória sobre 0 desenvolvimento de Cyperus rotundus (6). Extratos de Brassica napus inibiram eficientemente tanto a germinação como o crescimento da radícula de alface e tomateiro. A colza pode afetar o desenvolvimento de outras espécies cultivadas em sucessão a ela (9).

O objetivo deste trabalho foi estudar a ação alelopática de extratos aquosos de Cyperus rotundus, Sorghum halepense, Cynodon dactylon, Canavalia ensiformis e Brassica napus

na germinação do indicador Lycopersicon esculentum Mill. cv. Santa Cruz.

\section{MATERIAIS E MÉTODOS}

Neste ensaio, realizado no Departamento de Botânica da UNESP - Botucatu, foram utilizadas plantas no estado vegetativo, procedentes dos campos experimentais da E.S.A. "Luiz de Queiroz", Piracicaca (SP). O material coletado constou das seguintes espécies : Cyperus rotundus L. (tiririca), Sorghum halepense L. (capim massambará), Cynodon dactylon L. (grama seda), Canavalia ensiformis D.C. 
(feijão-de-porco) e Brassica napus L. (col$\mathrm{za})$.

Os tubérculos de C. rotundus foram isolados, lavados, secos ao ar e pesados, sendo que foi adicionada água destilada na proporção de $2: 1$ previamente à homogeneização. Os rizomas de $S$. halepense foram homogeneizados após a adição de água destilada $5: 1$. 0 sistema radicular de C. dactylon foi também estudado em sloução aquosa 5 : 1 . Em $C$. ensiformis utilizou-se $100 \mathrm{ml}$ de água destilada para 12,5 g de folhas e $100 \mathrm{ml}$ de água para 18,9 $\mathrm{g}$ de sistema radicular. Finalmente, em B. napus usou-se $100 \mathrm{ml}$ de água destilada para $24,4 \mathrm{~g}$ de folhas e $100 \mathrm{ml}$ de água para 18,5 g de raízes.

No preparo do extrato aquoso, esses materiais foram triturados separadamente em liquidificador e homogeneizador Virtis 45 , sendo que o extrato obtido foi submetido à filtragem em funil Buchner com papel de filtro Whatman $\mathrm{n} \gg 1$. 0 extrato foi em seguida centrifugado durante 10 minutos a $2000 \mathrm{rpm}$ em centrífuga Sorval SS-4. O extrato utilizado foi o sobrenadante límpido obtido após a centrifugação. Para C. rotundus, S. halepense e C. dactylon foram utilizados extratos puros e diluídos a 50\% com água destilada. Os extratos foram mantidos em Freezer Revco com temperatura controlada a $5^{\circ} \mathrm{C}$

Com a finalidade de verificar o efeito dos extratos assim obtidos, na germinação do tomateiro (Lycopersicon esculentum Mill. cv. Santa Cruz), $10 \mathrm{ml}$ do ex trato foi adicionado por placa de Petri, previamente preparada com algodão e papel de filtro, contendo 10 sementes de tomateiro. Dez repetições for am manti das à temperatur a de $25^{\circ} \mathrm{C}$, sob luz difu sa, sendo que após 7 dias foi verificada a porcentagem de germinação e determinados os comprimentos da radícula e do hipocótilo.

\section{RESULTADOS E DISCUSSÃO}

De acord o com a figura 1, verificouse que o extrato aquoso puro dos tubérculos de $C$. rotundus inibiu totalmente a germinação das sementes do tomateiro 'Santa Cruz'. Extrato diluído $(50 \%)$ de C. rotundus tam bém reduziu a porcentagem de germinação das sementes da planta indic adora. A ação alelopática de C. rotundus no des envolvimento de plantas cultivadas foi descrita por Rice (10) e por Bell e Koeppe (1), sendo que Tames et al (12) também observaram que tubérculos de tiririca inibiram o processo de germinação do tomateiro. $\mathrm{O}$ extrato diluído de $C$. rotundus diminuiu pronunciadamente o crescimento da radícula e do hipocótilo em relação ao controle ( figura 1 ).

Pela figura 2 notou-se que o extrato $100^{\circ} \%$ o dos rizomas de $S$. halepense inibiu completamente a germinação de L. esculentum cv. Santa Cruz. Extrato 50\% capim massambará também diminuiu a porcentage $m$ de germina ção das semen tes de tomateiro. O extrato diluído de $S$. halepense reduziu o desenvolvimento da radícula e do hipocótilo da planta teste com relação ao controle. O efeito alelopático de Sorghum spp. foi também observado por Overland (8) e Rice (10). 


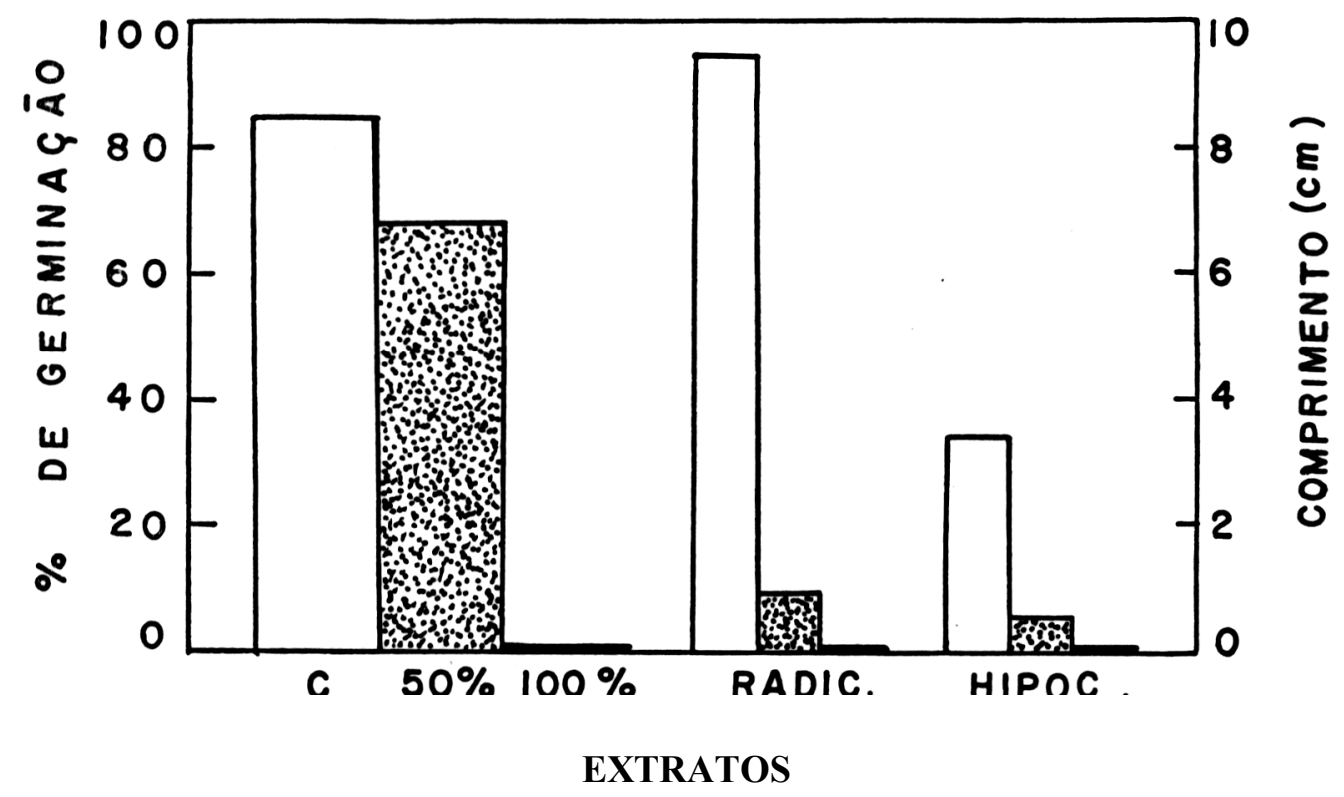

Figura 1 - Histograma representativo dos valores relativos a porcentagem de germinação e comprimento da radícula e hipocótilo do to mateiro, determinados 7 dias após a semeadura, em placas de Petri umidecidas com 0 , $50 \%$ e $100 \%$ do extrato de tubérculos de Cyperus rotundus.



Figura 2 - Histograma representativo dos valores relativos a porcentagem de germinação e comprimento da radícula e hipocótilo do to mateiro, determinados 7 dias após a semeadura, em placas de Petri umidecidas com $0,50 \%$ e $100 \%$ do extrato de rizomas deSorghum halepense. 


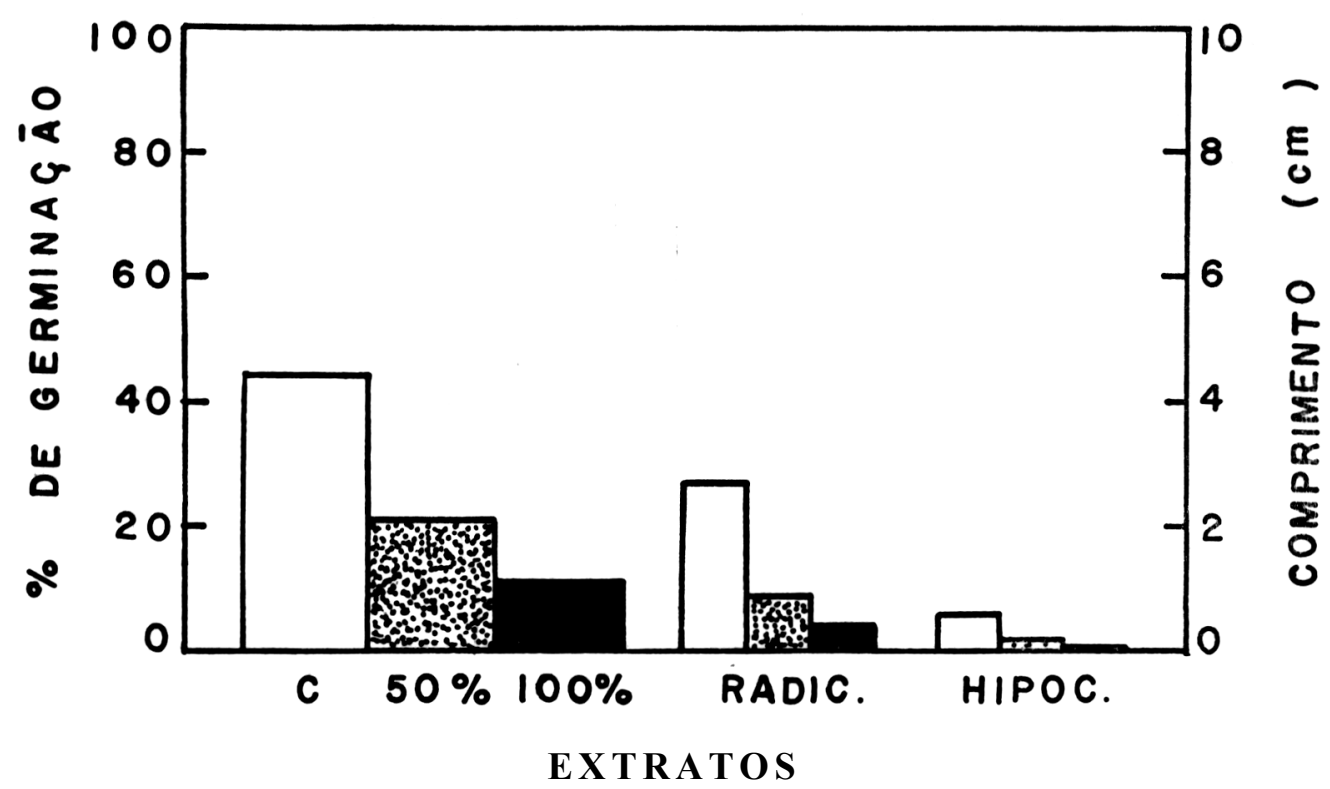

Figura 3 - Histog rama representativo dos valores relativos a porcentagem de germinação e comprimento da radícula e hipocótilo do tomateiro, determinados 7 dias após a semeadura, em placas de Petri umidecidas com 0, $50 \%$ e $100 \%$ do extrato do sistema radicular de Cynodon dactylon.

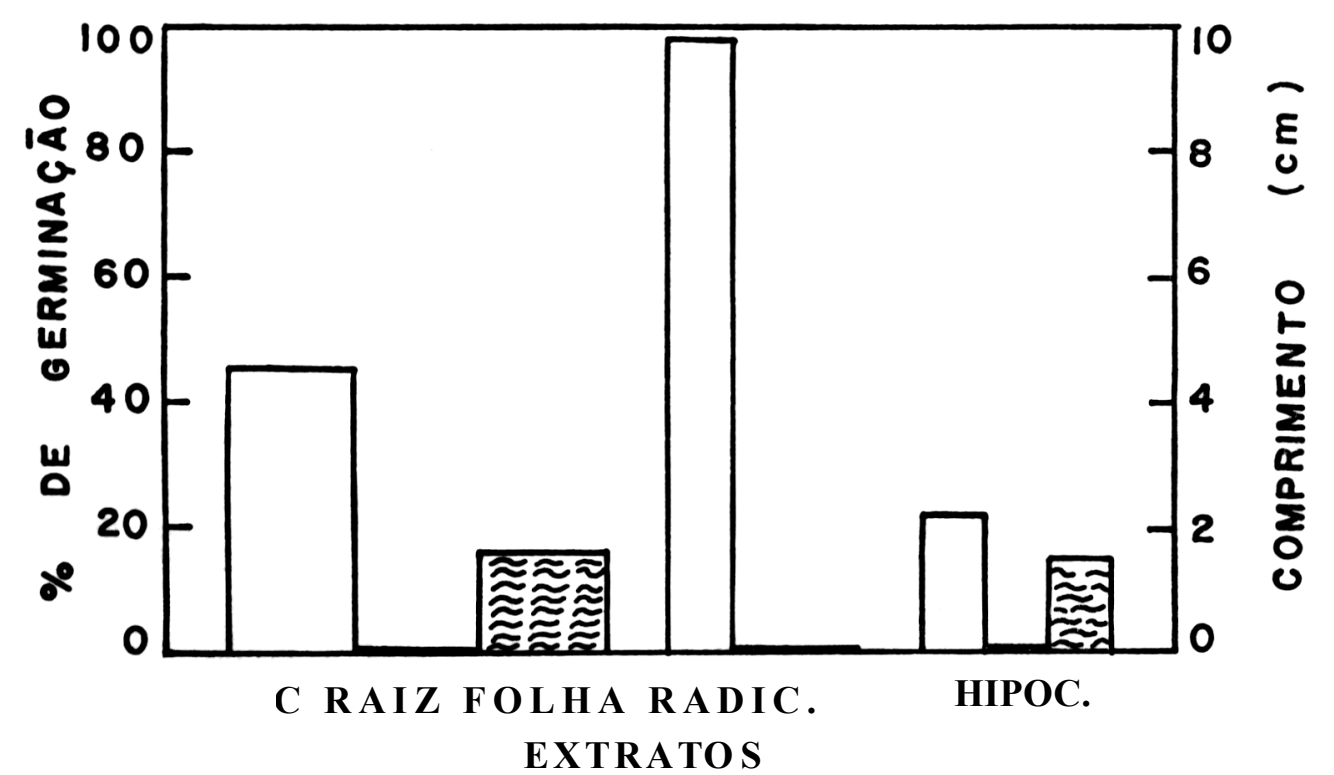

Fig ura 4 - Histograma representativo dos valores relativos a porcentagem de germinação e comprimento da radícula e hipocótilo do to mateiro, determinados 7 dias após a semeadura, em placas de Petri umidecidas com água destilada, extrato de raízes e extrato de folhas de Canavalia ensiformis. 


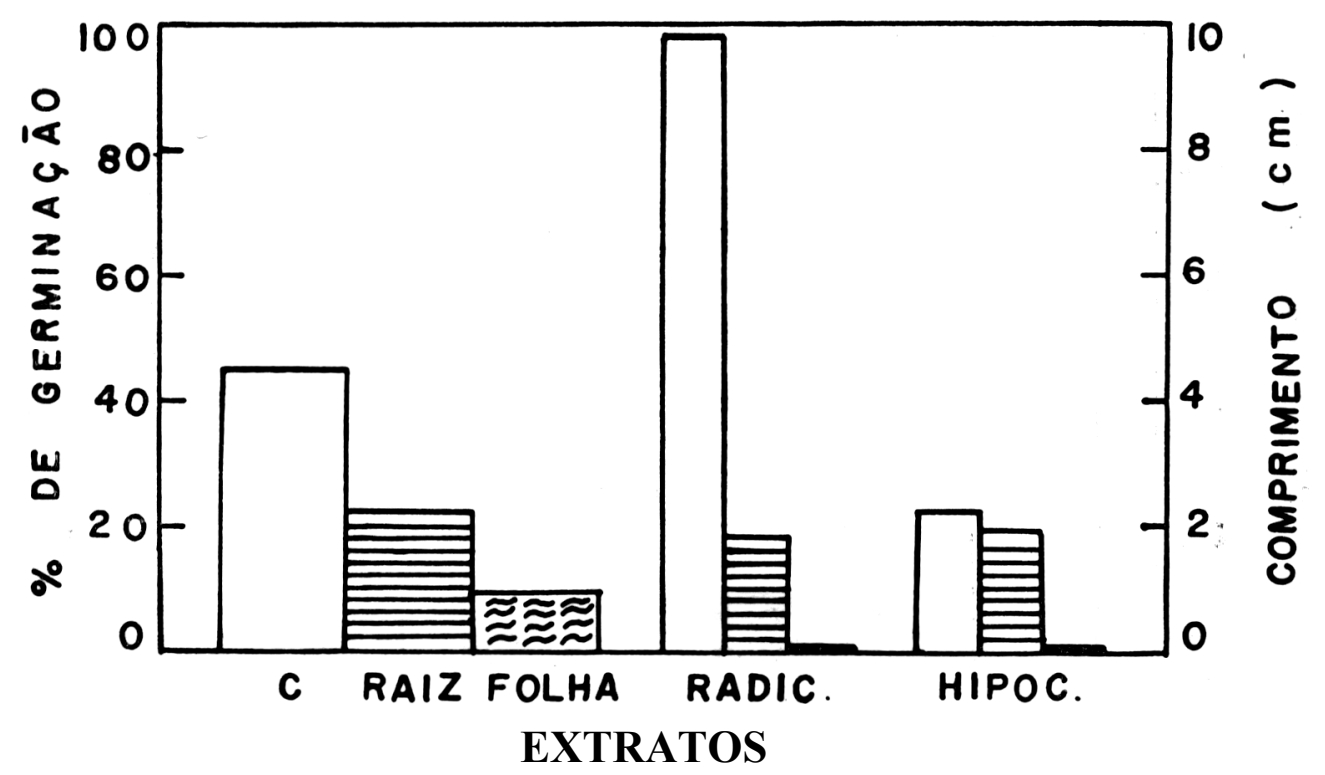

Figura 5 - His tograma representativo dos valores relativos a porcentagem de germinação e comprimento da radícula e hip ocótilo do to mateiro, determinados 7 dias após a semeadura, em placas de Petri umidecidas com água destilada, extrato de raízes e extrato de folhs de Brassica napus.

Verificaram-se que os extratos aquosos do sistema radicular de Cynodon dactylon inibiram a germinação e o crescimento da radícula e do hipocótilo da planta indicadora, proporcionalmente a concentração utilizada ( figura 3 ). Chou e Young (2) notaram a presença de fitotoxinas em C. dactylon, as quais mostraram efeito inibitório na germinação de alfafa.

De acordo com a figura 4, pode-se considerar que o extrato de raízes de Canavalia ensiformis inibiu mais eficientemente a germinação e o crescimento inicial do tomateiro do que o extrato de folhas. Magalhães e Franco (6) também verificaram maior eficiência do efeito alelopático do sistema radicular de $C$. ensiformis no desenvolvimento da tiririca.

Pela figura 5, notou-se que as folhas de Brassica napus afetaram mais eficientemente a germinação da planta indicadora, sendo que o extrato de raízes também diminuiu a germinação e o crescimento inicial do tomateiro 'Santa Cruz'. Peters et al (9) observaram inibição na germi- nação de sementes de tomateiro por extratos de colza.

Os resultados obtidos permitem considerar que os tubérculos de C. rotundus, os rizomas de $S$. halepense e o sistema radicular de C. ensiformis poss uem substâncias altamente inibitória s a germinação do tomateiro 'Santa Cruz'. A planta indicadora também mostrou-se sensível às sub stâncias presentes nas fol has de $B$. napus e no sistema radicular de $C$. dactylon.

\section{LITERATURA GITADA}

1. Bell, D.T. \& Koeppe, D.E. Noncompetitive effects of giant foxtail on the growth of corn. Agron. J., 64: 321-325, 1972.

2. Chou, C.H. \& Young, C.C. Phytotoxic substances in twelve sub-tropical grasses. $J$. Chem. Ecol., 1: 183-193, 1975.

3. Coutinho, L.M. \& Hashimoto, F. Sobre o efeito inibitório da germinação de sementes produzido por folhas de Calea cuneifolia DC. Ciência e Cultura 23 (6): 759-764, 1971

4. Einhellig, F.A. Allelopathic chemicals in crop regulation. Proc. Plant Growth Regul. Soc. Amer., St. Petersburg, 8: 40-51, 1981. 
5. Kanchan, S.D. \& Jayachandra. Allelopathic effects of Parthenium hysterophorus L. I. Exudation of inhigitors through roots. Plant Soil, 53: 27-35, 1979.

6. Magalhães, A.C.N. \& Franco, C.M. Toxicidade do feijão-de-porco sobre a "tiririca". Bragantia, 21 (1): 6 p., nota n. 9, 1962.

7. Massey, A.B. Antagonism of the walnuts (Juglans nigra L. and J. cinerea L.) in certain plant association. Phytopathology, 15: 773-784, 1925.

8. Overland, L. The role of allelopathic substances in the "smother crop" barley. Amer. J. Bot., 53: 423-432, 1966.
9. Peters, J.A.; Gastal, M.F.C. \& Finger, F.L. Estudo das possíveis proprieddaes alelopáticas da colza (Brassica napus L.). Res. Congr. Bras. Herb. Erv. Dan., Campinas, 14: $14-15,1982$.

10. Rice, E.L. Allelopathy - An update. Bot. Rev. 45 (1): 15-109, 1979.

11. Ries, S.K.; Wert, V.; Sweeley, C.C. \& Leavitt, R. A. Triacontanol: A new naturally occurring plant growth regulator. Science, 195: 1339-1341, 1977.

12. Tames, R.S.; Gesto, M.D.V. \& Vieitz, E. Growth substances isolated from tubers of Cyperus esculentus var. aureus. Physiol. Pl., 28: 195-200, 1973. 